\title{
Estimativa da necessidade de nitrogênio em cobertura no feijoeiro IAC Alvorada com clorofilômetro portátil ${ }^{1}$
}

\author{
Sidedressing nitrogen need estimation on common bean IAC \\ Alvorada using chlorophyll meter
}

\author{
Suelen Cristina Mendonça Maia ${ }^{2 *}$; Rogério Peres Soratto ${ }^{3}$; \\ Flávia de Oliveira Biazotto ${ }^{4}$; Adriana Queiroz de Almeida ${ }^{5}$
}

\section{Resumo}

\begin{abstract}
Objetivou-se avaliar a eficiência do índice de suficiência de nitrogênio (ISN) de $90 \%$ e 95\%, calculado com base no índice relativo de clorofila (IRC) nas folhas das plantas da área referência, como indicador do momento de aplicação da adubação nitrogenada de cobertura no feijoeiro cultivar IAC Alvorada. Um experimento com cinco manejos de N (M1: $200 \mathrm{~kg} \mathrm{ha}^{-1}$ (40 kg na semeadura $+80 \mathrm{~kg} 15$ dias após a emergência (DAE) + $80 \mathrm{~kg} 30 \mathrm{DAE}) ; \mathrm{M} 2: 100 \mathrm{~kg} \mathrm{ha}^{-1}(20 \mathrm{~kg}$ na semeadura $+40 \mathrm{~kg} 15 \mathrm{DAE}+40 \mathrm{~kg}$ 30 DAE); M3: $20 \mathrm{~kg} \mathrm{ha}^{-1}$ na semeadura e $30 \mathrm{~kg} \mathrm{ha}^{-1}$ quando o ISN $<95 \%$; M4: $20 \mathrm{~kg} \mathrm{ha}^{-1}$ na semeadura e $30 \mathrm{~kg} \mathrm{ha}^{-1}$ quando o ISN $<90 \%$ e M5: testemunha sem N) e quatro repetições, foi conduzido nas safras "das águas" e "da seca" no ano agrícola de 2009/10, em Botucatu (SP). Foram avaliados o IRC, massa de matéria seca da parte aérea, teor de $\mathrm{N}$ nas folhas, componentes de produção, produtividade de grãos e eficiência de utilização do N aplicado. A utilização do ISN de $90 \%$, calculado com base no monitoramento do IRC nas folhas com o clorofilômetro portátil, é mais eficiente que o de $95 \%$ para a definição de quando se deve aplicar o $\mathrm{N}$ em cobertura no feijoeiro cultivar IAC Alvorada, possibilitando o uso de menores doses de N, com maior eficiência do fertilizante aplicado.

Palavras-chave: Phaseolus vulgaris, clorofila, índice relativo de clorofila, índice de suficiência de nitrogênio
\end{abstract}

\begin{abstract}
The aims of this study was evaluated the efficiency of nitrogen sufficiency index (NSI) calculated with base on the measures relative chlorophyll index (RCI) leaves, measured with portable chlorophyll meter, as an indicator of time of sidedressing $\mathrm{N}$ fertilization and verify which value of NSI $(90 \%$ and $95 \%$ ) is the most appropriate to indicate the moment of $\mathrm{N}$ fertilization on common bean cultivar IAC Alvorada. An experiment with five N managements (M1: $200 \mathrm{~kg} \mathrm{ha}^{-1} \mathrm{~N}(40 \mathrm{~kg}$ at sowing $+80 \mathrm{~kg}$ at 15 days after emergency (DAE) $+80 \mathrm{~kg} 30 \mathrm{DAE}) ; \mathrm{M} 2: 100 \mathrm{~kg} \mathrm{ha}^{-1} \mathrm{~N}(20 \mathrm{~kg}$ at sowing $+40 \mathrm{~kg}$ at 15 $\mathrm{DAE}+40 \mathrm{~kg}$ at $30 \mathrm{DAE}) ; \mathrm{M} 3: 20 \mathrm{~kg} \mathrm{ha}^{-1} \mathrm{~N}$ at sowing $+30 \mathrm{~kg} \mathrm{ha}^{-1}$ when chlorophyll meter readings indicated NSI $<95 \%$; M4: $20 \mathrm{~kg} \mathrm{ha}^{-1} \mathrm{~N}$ at sowing $+30 \mathrm{~kg} \mathrm{~N}$ ha $^{-1} \mathrm{~N}$ when chlorophyll meter readings
\end{abstract}

\footnotetext{
${ }^{1}$ Parte da Dissertação de Mestrado da primeira autora, apresentada à Faculdade de Ciências Agronômicas, FCA, Universidade Estadual Paulista, UNESP, campus de Botucatu, SP. Trabalho financiado pela FAPESP, com bolsa de Mestrado à primeira autora (Proc. 2009/03730-4)

${ }^{2}$ Discente do Programa de Pós-Graduação em Agronomia (Agricultura), FCA/UNESP, Botucatu, SP. E-mail: suelen.maia@fca. unesp.br

${ }^{3}$ Prof. Adjunto do Dept ${ }^{\circ}$ de Produção e Melhoramento Vegetal, FCA/UNESP, C P 237, 18603-970, Botucatu, SP. Bolsista de produtividade em pesquisa do CNPq. E-mail: soratto@fca.unesp.br

${ }^{4}$ Discente do Curso de Graduação em Agronomia, FCA/UNESP, Botucatu, SP. E-mail: fdobiazotto@fca.unesp.br

${ }^{5}$ Pós-Doutoranda na Universidade Federal do Recôncavo da Bahia, Cruz das Almas, BA. E-mail: adrianaq_almeida@yahoo.com.br

* Autor para correspondência
} 
indicated NSI $<90 \%$ and, M5: control (without $\mathrm{N}$ application)) and four replications was carried out in the rainy and dry growing seasons of the agricultural year 2009/10, in Botucatu, São Paulo State, Brazil. The variables RCI, aboveground dry matter, leaf $\mathrm{N}$ concentration, yield components, grain yield, and $\mathrm{N}$ use efficiency were evaluated. The NSI of $90 \%$, calculated based on monitoring of RCI in common bean leaves with chlorophyll meter, was more effective than $95 \%$ to define need for $\mathrm{N}$ sidedressing in common bean cultivar IAC Alvorada, reducing the $\mathrm{N}$ application and improving the use efficiency of applied N.

Key words: Phaseolus vulgaris, chlorophyll, chlorophyll relative index, nitrogen sufficient index

O bom desenvolvimento do feijoeiro comum (Phaseolus vulgares L.) e a obtenção de altas produtividades de grãos dependem do emprego de tecnologias apropriadas, sendo que a suplementação adequada de nitrogênio $(\mathrm{N})$ destaca-se. $\mathrm{O} \mathrm{N}$ é o nutriente absorvido em quantidades mais elevadas pelo feijoeiro e, embora o feijoeiro supra parte da sua demanda de $\mathrm{N}$ pela associação com bactérias do gênero Rhizobium, a quantidade fornecida por esse processo normalmente é insuficiente, sendo necessária a utilização de adubação nitrogenada (SORATTO; CARVALHO; ARF, 2006; BARBOSA FILHO et al., 2008).

Normalmente, adubação nitrogenada mineral é definida pela análise visual da cultura ou por uma recomendação tradicional, baseada em curvas de resposta da planta ao $\mathrm{N}$, obtidas em experimentos de campo (SILVEIRA; BRAZ; DIDONET, 2003). Isso ocorre porque ainda não existe um método laboratorial eficiente para avaliar a capacidade do solo em fornecer $\mathrm{N}$ às plantas (BARBOSA FILHO et al., 2008). Porém, devido à complexa dinâmica do $\mathrm{N}$ aplicado ao solo (lixiviação, volatilização, imobilização-mobilização, nitrificação, desnitrificação, mineralização), é muito difícil saber se a dose recomendada para uma dada cultura é suficiente, possibilitando que as plantas alcancem o seu potencial produtivo, e/ou excessiva, o que aumenta os custos e os riscos ambientais (SILVEIRA; BRAZ; DIDONET, 2003). Além disso, as épocas de aplicação do adubo nitrogenado em cobertura, que consta nas recomendações são pré-definidas e podem não coincidir com momento de maior demanda do nutriente pela cultura (BARBOSA FILHO et al., 2009).
Neste contexto, a associação entre o monitoramento do nível de $\mathrm{N}$ na planta e da disponibilidade de $\mathrm{N}$ mineral do solo é muito importante para que se possa fazer a aplicação de $\mathrm{N}$ na época e quantidade adequadas. Esta tarefa é complexa, pois existem vários fatores que interferem na disponibilidade do $\mathrm{N}$ liberado pelo solo, bem como na velocidade de absorção e assimilação do nutriente pela planta (BREDEMEIER; MUNDSTOCK, 2000).

O parâmetro da planta mais estudado no intuito de indicar o nível de $\mathrm{N}$ na planta para predizer a necessidade de adubação de cobertura é o teor relativo de clorofila na folha. Este método fundamenta-se na correlação positiva existente entre o teor de clorofila e o teor de N na planta (SORATTO; CARVALHO; ARF, 2004; BARBOSA FILHO et al., 2008, 2009). Esta relação se deve ao fato de que $50 \%$ a $70 \%$ do $\mathrm{N}$ total das folhas ser integrante de enzimas que estão associadas ao cloroplasto (CHAPMAN; BARRETO, 1997).

Assim, o desenvolvimento do clorofilômetro, que permite, de forma não destrutiva, leituras instantâneas e indiretas do índice relativo de clorofila (IRC) nas folhas, as quais são correlacionadas positivamente com o teor de N (SILVEIRA; BRAZ; DIDONET, 2003; SORATTO; CARVALHO; ARF, 2004; BARBOSA FILHO et al, 2008, 2009), é uma alternativa para a indicação do nível de $\mathrm{N}$ na planta. O clorofilômetro apresenta facilidade de operação, podendo ser utilizado como ferramenta na tomada de decisão sobre a necessidade e momento de aplicação da adubação nitrogenada (BARBOSA FILHO et al., 2008, 2009). 
Para viabilizar a utilização do IRC, foi proposta por Barbosa Filho et al. (2008, 2009), a instalação de uma área de referência na lavoura onde se pretende manejar a adubação nitrogenada mediante o monitoramento com o clorofilômetro. A dose a ser aplicada na área de referência deve ser alta, entre 1,8 e 2,0 vezes a dose recomendada para a cultura, para permitir o desenvolvimento da concentração máxima de clorofila nas folhas. Sendo assim, foi calculado um índice de suficiência de N (ISN), pela relação entre o IRC nas folhas das plantas da lavoura e nas folhas das plantas da área de referência (sem deficiência de N), na qual é indicada a aplicação de N toda vez que o ISN das plantas da lavoura for inferior a 90\% do ISN da área de referência. Os autores conseguiram reduzir a dose de $\mathrm{N}$ aplicada, porém, a produtividade do feijoeiro na parcela maneja com auxílio do clorofilômetro foi significativamente inferior à da área referência, indicando que o uso do ISN de $90 \%$ da área referência pode ter levado a cultura do feijão a uma condição de deficiência de N.

No entanto, têm-se observado algumas divergências quanto ao índice de suficiência a ser utilizado como indicador da necessidade de aplicação nitrogenada em cobertura na literatura. De acordo com Varvel, Schepers e Francis (1997), para a cultura do milho, se o ISN for menor que $90 \%$ no estádio de oito folhas a deficiência de $\mathrm{N}$ não pode ser corrigida com a adubação de cobertura a ponto de maximizar a produtividade. Em contrapartida, Jemison e Lytle (1996), propuseram que ISN abaixo de 93\% indicam situações de deficiência de $\mathrm{N}$, enquanto que Varvel, Schepers e Francis (1997) utilizaram o índice de suficiência igual a 95\% para predizer a deficiência de $\mathrm{N}$ nessa cultura. Contudo, ainda existe a necessidade de se definir qual o ISN adequado para indicar o momento de adubação nitrogenada de cobertura na cultura do feijão. Assim, objetivou-se com o presente trabalho avaliar a eficiência do ISN de 90\% e 95\%, calculado com base no IRC nas folhas das plantas da área referência, medido com clorofilômetro portátil, como indicador do momento de aplicação da adubação nitrogenada de cobertura no feijoeiro cultivar IAC Alvorada.

O trabalho foi realizado durante as safras "das águas" e "da seca" do ano agrícola 2009/2010,


de altitude). O clima, conforme a classificação de Köppen é do tipo Cwa, que se caracteriza como tropical de altitude, com inverno seco e verão quente e chuvoso.

O experimento foi conduzido em áreas sob sistema plantio direto há aproximadamente dez anos. Na safra "das águas", a semeadura do feijão acorreu em 12/08/2009, em área anteriormente ocupada pela sucessão milho/aveia branca/milho, já na safra "da seca" a semeadura ocorreu em 09/02/2010 em área ocupada anteriormente pela sucessão milho/ aveia preta/milheto. O espaçamento utilizado foi de $0,45 \mathrm{~m}$ entrelinhas e densidade de semeadura de 16 sementes por metro.

O solo do local é classificado como Nitossolo Vermelho distroférrico. Antes da instalação do experimento em cada safra procederam-se amostragens de solo, na camada de 0-20 cm, para a determinação das características químicas. Na safra “das águas" os resultados foram: $\mathrm{pH}\left(\mathrm{CaCl}_{2}\right):=4,7$, M.O. $=27,0 \mathrm{~g} \mathrm{dm}^{-3}, \mathrm{P}($ resina $)=61 \mathrm{mg} \mathrm{dm}^{-3}, \mathrm{H}+\mathrm{Al}$, $\mathrm{K}, \mathrm{Ca}, \mathrm{Mg}$ e CTC $=53,3,3,24,10$ e $90 \mathrm{mmol}_{\mathrm{c}} \mathrm{dm}^{-3}$, respectivamente, e V $=41 \%$. Para a safra "da seca" foram obtidos: $\mathrm{pH}\left(\mathrm{CaCl}_{2}\right)=5,0$, M.O. $=30,0 \mathrm{~g} \mathrm{dm}^{-}$ 3. $\mathrm{P}($ resina $)=32 \mathrm{mg} \mathrm{dm}^{-3}, \mathrm{H}+\mathrm{Al}, \mathrm{K}, \mathrm{Ca}, \mathrm{Mg}$ e CTC $=73,2,2,30,17$ e $98 \mathrm{mmol}_{\mathrm{c}} \mathrm{dm}^{-3}$, respectivamente, e $\mathrm{V}=50 \%$.

O delineamento experimental usado foi o de blocos ao acaso com cinco tratamentos, constituídos por manejos de $\mathrm{N}$, aplicado na forma de nitrato de amônio, e quatro repetições. Os manejos de $\mathrm{N}$ foram M1: $40 \mathrm{~kg} \mathrm{ha}^{-1}$ de $\mathrm{N}$ na semeadura $+80 \mathrm{~kg} \mathrm{ha}^{-1}$ aos 15 dias após a emergência (DAE) $+80 \mathrm{~kg} \mathrm{ha}^{-1}$ aos 30 DAE, sendo este denominado de tratamento de referência (foi utilizado o dobro da dose máxima de $\mathrm{N}$ recomendada para a cultura (AMBROSANO et al., 1997), visando garantir a não ocorrência de 
deficiência de N); $\mathrm{M} 2: 20 \mathrm{~kg} \mathrm{ha}^{-1}$ de $\mathrm{N}$ na semeadura + $40 \mathrm{~kg} \mathrm{ha}^{-1}$ aos $15 \mathrm{DAE}+40 \mathrm{~kg} \mathrm{ha}^{-1}$ aos $30 \mathrm{DAE}$, dose baseada na recomendação local recomendada por Ambrosano et al. 1997; M3: $20 \mathrm{~kg} \mathrm{ha}^{-1}$ de N na semeadura $+30 \mathrm{~kg} \mathrm{ha}^{-1}$ quando as leituras do clorofilômetro indicaram ISN $<95 \%$; M4: $20 \mathrm{~kg} \mathrm{ha}^{-1}$ de $\mathrm{N}$ na semeadura $+30 \mathrm{~kg} \mathrm{ha}^{-1}$ quando as leituras do clorofilômetro indicaram ISN $<90 \%$ e, M5: testemunha (sem aplicação de N). Cada unidade experimental foi constituída por oito linhas com seis metros de comprimento, sendo que para área útil considerou as seis linhas centrais da parcela, desprezando $0,5 \mathrm{~m}$ na extremidade de cada linha de plantas.

A adubação básica de semeadura com fósforo e potássio, nas duas safras, foi de $40 \mathrm{~kg} \mathrm{ha}^{-1}$ de $\mathrm{P}_{2} \mathrm{O}_{5}$ e $40 \mathrm{~kg} \mathrm{ha}^{-1}$ de $\mathrm{K}_{2} \mathrm{O}$ nas formas de superfosfato simples e cloreto de potássio, respectivamente. Em ambas as safras, o fornecimento de água foi realizado por um sistema de irrigação convencional por aspersão, aplicando-se uma lâmina de 7,0 mm em cada aplicação e sempre durante as primeiras horas da manhã, de acordo com a necessidade da cultura.

As leituras do clorofilômetro (modelo Minolta SPAD-502) foram iniciadas aos 15 DAE (estádio $\mathrm{V}_{3}$ ) e a partir desta data as leituras foram tomadas semanalmente e prosseguiram até 64 DAE (estádio $\mathrm{R}_{8}$ ), realizadas em cinco plantas ao acaso por unidade experimental, sendo que em cada planta foram realizadas duas leituras por trifólio da última folha trifoliolada completamente expandida. As leituras foram realizadas na porção mediana do limbo foliar, evitando-se as nervuras, somando, assim 30 leituras por parcela.

O cálculo do ISN foi realizado através da relação dos valores de IRC (medidos com um clorofilômetro portátil, modelo Minolta SPAD-502) em cada parcela e na parcela referência. Após a determinação do IRC, as folhas amostradas foram imediatamente coletadas, submetidas à lavagem com água destilada, acondicionadas em sacos de papel e levadas à estufa para secagem e posteriormente moídas para análise do teor de N total (MALAVOLTA; VITTI; OLIVEIRA, 1997).

$\mathrm{Na}$ safra "das águas", houve necessidade de aplicação de N (ISN<95\%) no manejo M3 aos 15, 22 e 43 DAE, totalizando $110 \mathrm{~kg} \mathrm{ha}^{-1}$ de $\mathrm{N}$, já no manejo M4 o monitoramento com o clorofilômetro indicou necessidade de aplicação de $\mathrm{N}$ em cobertura apenas aos $22 \mathrm{DAE}$, totalizando assim $50 \mathrm{~kg} \mathrm{ha}^{-1} \mathrm{de}$ $\mathrm{N}$ aplicado. Na safra "da seca", o manejo M3 exigiu aplicação de $50 \mathrm{~kg} \mathrm{ha}^{-1}$ de $\mathrm{N}$, ou seja, cobertura apenas aos 37 DAE, enquanto no manejo M4 não foi necessário aplicação de $\mathrm{N}$ em cobertura.

O florescimento pleno $\left(\mathrm{R}_{6}\right)$ do cultivar IAC Alvorada durante as safras "das águas" e "da seca" ocorreu em 02/10/2009 (42 DAE) e 22/03/2010 (36 DAE), respectivamente.

Foram realizadas as seguintes avaliações: (a) massa de matéria seca da parte aérea das plantas: por ocasião do florescimento pleno, coletando-se oito plantas de cada parcela, colocadas em estufa com circulação forçada de ar a $60-70^{\circ} \mathrm{C}$, até atingir massa constante; (b) teor de $\mathrm{N}$ total nas folhas; (c) componentes da produção (população final de plantas, número de vagens/planta, número de grãos/ vagem e massa de 100 grãos); (d) produtividade de grãos: foram colhidos dos grãos em duas fileiras da área útil e a umidade foi corrigida para $0,13 \mathrm{~kg} \mathrm{~kg}^{-1}$, e (e) eficiência de utilização do nitrogênio aplicado (EU): determinada mediante a relação $\mathrm{kg} \mathrm{ha}^{-1}$ da produtividade incrementada $/ \mathrm{kg} \mathrm{ha}^{-1}$ de $\mathrm{N}$ aplicado em cada tratamento, em relação à testemunha.

Os dados obtidos em cada safra foram submetidos à análise de variância pelo teste F. As médias dos tratamentos foram comparadas pelo teste Tukey a $5 \%$ de probabilidade.

Os valores de IRC nas folhas do feijoeiro, em ambas as safras, foram crescentes com o tempo, principalmente até 36 DAE (florescimento pleno), praticamente se estabilizando a partir dessa época (Figuras 1A e 1B), o que se justifica pelo fato de que após o florescimento o teor de clorofila nas folhas se 
estabiliza, e após esta fase de crescimento a resposta do feijoeiro ao $\mathrm{N}$ é pequena, provavelmente devido à maior contribuição da fixação biológica do $\mathrm{N}_{2}$ e da redistribuição do elemento na planta para outros tecidos, corroborando os resultados obtidos por Silveira, Braz e Didonet (2003) e Barbosa Filho et al. (2008, 2009).

$\mathrm{Na}$ fase inicial de crescimento do feijoeiro na safra "das águas", os valores dos IRC do tratamento sem aplicação de N (M5) encontravam-se abaixo das leituras obtidas nas parcelas adubadas, porém, a partir dos 50 DAE, as plantas do M5 apresentaram valores de IRC muito próximos das leituras observadas nas parcelas adubadas com N (Figura 1A). Durante todo o período de crescimento na safra "da seca", os valores dos IRC do tratamento sem aplicação de N (M5) encontravam-se muito próximos das leituras observadas nas parcelas adubadas com N (Figura 1B). Esse comportamento pode ser explicado pelo processo de mineralização do $\mathrm{N}$ dos resíduos vegetais deixados na superfície do solo ou pelo processo de fixação simbiótica do $\mathrm{N}_{2}$ atmosférico que sob condições ambientais adequadas, pode atender parte das necessidades do feijoeiro por $\mathrm{N}$, mediante associação com bactérias do gênero Rhizobium (SOARES et al., 2006). Barbosa Filho et al. (2008) observaram que, a partir do florescimento, as plantas de feijão do tratamento testemunha apresentavam tonalidade verde mais intenso, resultando em valores de IRC muito próximos às leituras observadas nas parcelas adubadas com $\mathrm{N}$ e relataram que esse fato ocorreu em função da mineralização do $\mathrm{N}$ contido nos resíduos vegetais.
$\mathrm{Na}$ avaliação realizada aos $15 \mathrm{DAE}$, durante a safra "das águas", no manejo M3 no qual a aplicação de $\mathrm{N}$ foi realizada mediante o monitoramento com o clorofilômetro (ISN<95\%), foram obtidos valores de ISN de 93\%, indicando a necessidade da primeira cobertura, e o manejo M4, baseado no ISN de $90 \%$, não apresentou índice abaixo do limite mínimo definido, não necessitando de aplicação do N em cobertura (Figura 1C). Na safra "da seca" verificou-se que os manejos monitorados pelo clorofilômetro (manejo M3 = 95\% e manejo M4 $=90 \%$ ) não determinaram ISN abaixo do limite mínimo estabelecido, dispensando a adubação em cobertura (Figura 1D).

O manejo M4, durante a safra "da seca", não apresentou ISN abaixo do definido como mínimo em nenhuma das datas de avaliação, não sendo necessária aplicação do $\mathrm{N}$ em cobertura. Assim, o tratamento M4 recebeu apenas $20 \mathrm{~kg} \mathrm{ha}^{-1}$ de $\mathrm{N}$ na semeadura.

Aos 22 DAE, durante o cultivo da safra "das águas", o feijoeiro apresentou valores de ISN de $93 \%$ e $86 \%$ para os tratamentos M3 e M4, respectivamente (Figura 1C). Esses valores indicaram a necessidade da aplicação de cobertura com $\mathrm{N}$, época em que foram aplicados os $30 \mathrm{~kg} \mathrm{ha}^{-1}$ de N. Aos 29 e 36 DAE, os valores de IRC verificados no tratamento referência (M1) foram semelhantes aos observados nos demais manejos com aplicação de N (M2, M3, M4). Assim, os valores de ISN dos tratamentos M3 e M4 foram maiores que os índices pré-estabelecidos para cada um desses tratamentos, dispensando a adubação em cobertura nestas datas. 
Figura 1. Índice relativo de clorofila (A e B), índice de suficiência de $\mathrm{N}(\mathrm{C}$ e D) e teor de $\mathrm{N}$ nas folhas $(\mathrm{E}$ e $\mathrm{F})$ no feijoeiro cultivar IAC Alvorada em diferentes épocas de avaliação, em função do manejo da adubação nitrogenada de cobertura, na safra "das águas" e "da seca". M1 $=40+80+80 \mathrm{~kg} \mathrm{ha}^{-1}, \mathrm{M} 2=20+40+40 \mathrm{~kg} \mathrm{ha}^{-1}, \mathrm{M} 3=20 \mathrm{~kg} \mathrm{ha}^{-1} \mathrm{de}$ $\mathrm{N}$ na semeadura $+30 \mathrm{~kg} \mathrm{ha}^{-1}$ quando ISN $<95 \%$; M $4=20 \mathrm{~kg} \mathrm{ha}^{-1}$ de $\mathrm{N}$ na semeadura $+30 \mathrm{~kg} \mathrm{ha}^{-1}$ quando o ISN $<90 \%$ e, M5 = testemunha, sem aplicação de N. Barras verticais são indicativas do valor de DMS pelo teste de Tukey a 5\% de probabilidade.
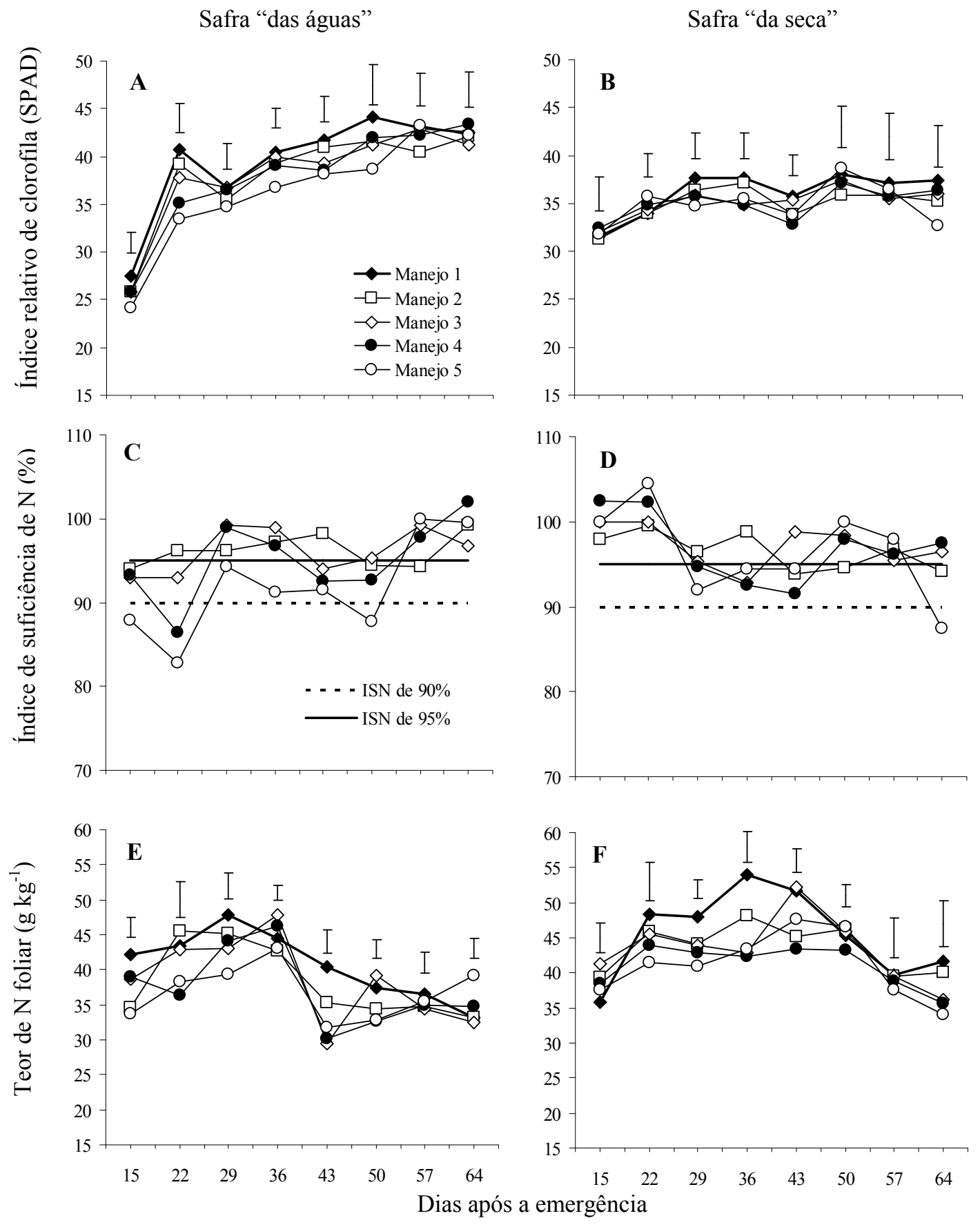

Fonte: Elaboração dos autores. 
$\mathrm{Na}$ safra "da seca", as plantas do manejo M3 apresentaram aos 36 DAE valores de ISN inferiores a $95 \%$ do observado no tratamento referência (M1) (Figura 1D), necessitando da aplicação de $\mathrm{N}$ em cobertura, época em que foram aplicados os $30 \mathrm{~kg} \mathrm{ha}^{-1}$ de N. Com 43 DAE, foram constatados valores de ISN de 94\% no manejo M3 (ISN<95\%), indicando a necessidade da aplicação de $\mathrm{N}$, época em que foram aplicados os $30 \mathrm{~kg} \mathrm{ha}^{-1}$ de $\mathrm{N}$ na safra das "águas" (Figura 1C). No manejo M4 (ISN<90\%) os valores de ISN, estavam acima do valor definido como limite mínimo para não aplicação de $\mathrm{N}$ em cobertura. Os ISN calculados a partir dos 50 DAE para os manejos M3 e M4 não apresentaram valores abaixo dos estabelecidos como indicativo de necessidade de aplicação de $\mathrm{N}$ em cobertura, resultado explicado pela estabilização dos IRC a partir dos 50 DAE, ou seja, as diferença nos valores de IRC entre os tratamentos, foram pequenas (Figura 1A).

$\mathrm{Na}$ safra "das águas", o teor de $\mathrm{N}$ foliar no manejo M1 apresentou acréscimos até 29 DAE, época em que o teor foliar determinado foi máximo e correspondente ao estágio $\mathrm{V}_{4-5}$ do cultivar, decrescendo a partir dessa época (Figura 1E). Os demais manejos apresentaram teores crescentes com o tempo, sendo que, os teores máximos foram observados aos $36 \mathrm{DAE}$, época correspondente ao início da fase reprodutiva $\left(\mathrm{R}_{5}\right)$, decrescendo a partir dessa data. Isto pode indicar que os teores máximos de $\mathrm{N}$ nas folhas do cultivar IAC Alvorada, durante a safra "das águas", ocorreram durante a fase vegetativa. A diminuição do teor de $\mathrm{N}$ foliar a partir do início da fase reprodutiva pode indicar um efeito de diluição, que nessa fase ocorre grande acumulo de matéria seca pelas plantas e/ ou que o $\mathrm{N}$ é mobilizado das folhas para estruturas reprodutivas, uma vez que, a planta prioriza as suas sementes como forma de sobrevivência da espécie, diminuindo a sua concentração nas folhas.

$\mathrm{Na}$ safra "da seca" os teores de $\mathrm{N}$ nas folhas foram crescentes até o início do estádio $\mathrm{R}_{7}$ (43 DAE), decrescendo a partir dessa fase (Figura 1F). Nota-se que, especialmente entre 29 e 36 DAE (início da fase reprodutiva), os tratamentos que receberam maiores quantidades de $\mathrm{N}$ apresentaram maiores teores do elemento nas folhas. No manejo M1 (referência), os teores máximos de $\mathrm{N}$ foliar ocorreram durante a fase de florescimento $\left(\mathrm{R}_{6}\right)$ e início da formação de vagens $\left(R_{7}\right)$. Sant'Ana, Santos e Silveira (2010) verificaram que o teores de $\mathrm{N}$ nas folhas do feijoeiro, determinados durante o florescimento, apresentaram valores mais elevados com a aplicação das maiores doses de N. Vale ressaltar que, em ambos os cultivares, todos os tratamentos apresentaram valores acima do limite mínimo da faixa indicada como adequada por Ambrosano et al. (1997), ou seja, de $30 \mathrm{~g} \mathrm{~kg}^{-1}$, em todas as épocas de avaliação. Isso pode ser explicado, provavelmente, devido à elevada disponibilidade de $\mathrm{N}$ no solo, decorrente da mineralização dos resíduos vegetais deixados na superfície do solo pelos cultivos anteriores e/ ou pelo processo da fixação simbiótica do $\mathrm{N}_{2}$, que sob condições ambientais adequadas, pode atender parte das necessidades do feijoeiro por N, mediante associação com bactérias do gênero Rhizobium (SOARES et al., 2006).

Na safra “das águas”, os manejos M1 (referência) e M3 (ISN $<95 \%)$ apresentaram os maiores valores de massa de matéria seca na parte aérea (6,1 e 6,0 g planta ${ }^{-1}$, respectivamente), diferindo estatisticamente do tratamento que recebeu a menor dose de N (M4) e da testemunha (M5) (Tabela 1). Já na safra "da seca" as maiores produções de matéria seca na parte aérea foram proporcionadas pelos tratamentos M1 e M2 (7,5 e 7,3 g planta $^{-1}$, respectivamente), que diferiram significativamente apenas do tratamento testemunha (M5) (Tabela 1). $\mathrm{O}$ acréscimo na dose de $\mathrm{N}$ aplicada aumenta a disponibilidade desse nutriente, dessa forma um incremento na absorção pelas plantas é observado, promovendo a produção de matéria seca, uma vez que o $\mathrm{N}$ tem extrema importância para a produção de matéria seca, por ser parte constituinte da molécula de clorofila e, portanto, ter influência na fotossíntese e promovendo o crescimento vegetativo 
do feijoeiro (SILVEIRA; DAMASCENO, 1993). Pesquisas confirmaram o aumento do acúmulo da massa de matéria seca na parte aérea do feijoeiro, com a aplicação de N em cobertura (SILVEIRA; DAMASCENO, 1993; SORATTO; CARVALHO; ARF, 2004, 2006; SOARES et al., 2006).

Tabela 1. Dose de N aplicada, massa de matéria seca da parte aérea, número de vagens por planta, número de grãos por vagem, massa de 100 grãos, produtividade de grãos e eficiência de utilização do $\mathrm{N}$ aplicado (EU) do feijoeiro cv. IAC Alvorada, em função dos manejos de N, nas safras "das águas" e "da seca".

\begin{tabular}{|c|c|c|c|c|c|c|c|}
\hline $\begin{array}{c}\text { Manejo } \\
\text { do N }\end{array}$ & $\begin{array}{c}\text { Dose de N } \\
\text { aplicada }\end{array}$ & $\begin{array}{c}\text { Matéria } \\
\text { seca }\end{array}$ & $\begin{array}{l}\text { Vagens por } \\
\text { planta }\end{array}$ & $\begin{array}{l}\text { Grãos por } \\
\text { vagem }\end{array}$ & $\begin{array}{l}\text { Massa de } \\
100 \text { grãos }\end{array}$ & $\begin{array}{l}\text { Produtividade de } \\
\text { grãos }\end{array}$ & EU \\
\hline & $\mathrm{kg} \mathrm{ha}^{-1}$ & g planta ${ }^{-1}$ & — nún & ro & g & $\mathrm{kg} \mathrm{ha}^{-1}$ & $\begin{array}{l}\text { kg grãos por } \\
\text { kg de N }\end{array}$ \\
\hline & \multicolumn{7}{|c|}{ Safra "das águas" } \\
\hline M1 & 200 & $6,1 \mathrm{a}$ & $15,1 \mathrm{a}$ & $4,2 \mathrm{a}$ & $29,5 \mathrm{a}$ & $3.368 \mathrm{a}$ & 3,3 \\
\hline M2 & 100 & $5,2 \mathrm{ab}$ & $13,4 \mathrm{a}$ & $4,4 \mathrm{a}$ & $30,0 \mathrm{a}$ & $3.025 \mathrm{ab}$ & 3,1 \\
\hline M3 & 110 & $6,0 \mathrm{a}$ & $14,5 \mathrm{a}$ & $4,3 \mathrm{a}$ & $28,6 \mathrm{a}$ & $2.933 \mathrm{ab}$ & 2,0 \\
\hline M4 & 50 & $4,3 b$ & $13,4 \mathrm{a}$ & $4,3 \mathrm{a}$ & $31,4 \mathrm{a}$ & $3.061 \mathrm{ab}$ & 7,0 \\
\hline M5 & 0 & $4,0 \mathrm{~b}$ & $12,2 \mathrm{a}$ & $4,2 \mathrm{a}$ & $30,6 a$ & $2.711 \mathrm{~b}$ & - \\
\hline \multirow[t]{2}{*}{ CV (\%) } & - & 10,6 & 18,4 & 5,4 & 3,1 & 8,8 & - \\
\hline & \multicolumn{7}{|c|}{ Safra "da seca" } \\
\hline M1 & 200 & $7,5 \mathrm{a}$ & $7,8 \mathrm{a}$ & $3,8 \mathrm{a}$ & $33,0 \mathrm{a}$ & $2.798 \mathrm{a}$ & 1,6 \\
\hline M2 & 100 & $7,3 \mathrm{a}$ & $6,3 \mathrm{a}$ & $4,8 \mathrm{a}$ & $32,0 \mathrm{a}$ & $2.622 \mathrm{a}$ & 1,5 \\
\hline M3 & 50 & $6,3 \mathrm{ab}$ & $6,3 a$ & $4,3 \mathrm{a}$ & $33,0 \mathrm{a}$ & $2.880 \mathrm{a}$ & 8,1 \\
\hline M4 & 20 & $6,0 \mathrm{ab}$ & $6,5 \mathrm{a}$ & $4,8 \mathrm{a}$ & $33,3 \mathrm{a}$ & $2.735 \mathrm{a}$ & 13,0 \\
\hline M5 & 0 & $5,5 \mathrm{~b}$ & $6,5 \mathrm{a}$ & $4,3 a$ & $34,0 \mathrm{a}$ & $2.476 \mathrm{a}$ & - \\
\hline $\mathrm{CV}(\%)$ & - & 12,9 & 12,1 & 17,0 & 3,7 & 10,2 & - \\
\hline
\end{tabular}

Médias seguidas da mesma letra na coluna, dentro de cada safra, não diferem estatisticamente entre si pelo teste de Tukey ( $p \leq 0,05)$. $\mathrm{M} 1=40+80+80 \mathrm{~kg} \mathrm{ha}^{-1}, \mathrm{M} 2=20+40+40 \mathrm{~kg} \mathrm{ha}^{-1}, \mathrm{M} 3=20 \mathrm{~kg} \mathrm{ha}^{-1}$ de N na semeadura $+30 \mathrm{~kg}^{-1}$ quando as leituras do clorofilômetro indicaram ISN $<95 \%$; M4 $=20 \mathrm{~kg} \mathrm{ha}^{-1} \mathrm{de} \mathrm{N}$ na semeadura $+30 \mathrm{~kg} \mathrm{ha}^{-1}$ quando as leituras do clorofilômetro indicaram ISN $<90 \%$ e, M5 = testemunha, sem aplicação de N.

Fonte: Elaboração dos autores.

A população final de planta não foi afeta pelos manejos do $\mathrm{N}$ em nenhuma das safras. Durante as duas safras, não foram constatadas diferenças significativas para o número de vagens por planta em função dos manejos de $\mathrm{N}$ aplicados (Tabela 1). Esses resultados corroboram Gomes Júnior, Sá e Valério Filho (2008), que não obtiveram resposta quanto ao número de vagens por planta com a aplicação de $\mathrm{N}$ em cobertura no feijoeiro. Apesar das grandes diferenças na matéria seca da parte aérea das plantas no estádio $\mathrm{R}_{6}$ proporcionadas pelos manejos do $\mathrm{N}$, a ausência de efeito no número de vagens por planta pode ter sido devido a um efeito de compensação, ou seja, formação e pegamento de flores formadas mais tardiamente, já que ambos os cultivares possuem hábito de crescimento indeterminado (tipo II ou III).

O número de grãos por vagem não foi influenciado significativamente pelos manejos de $\mathrm{N}$ aplicados nas duas safras (Tabela 1), provavelmente porque essa característica seja intrínseca ao cultivar (genótipo) utilizado, sofrendo pouca influência das práticas culturais. Além disso, esta característica geralmente não apresenta correlação com a produtividade de grãos (SORATTO; CARVALHO; ARF, 2004). 
Soratto, Carvalho e Arf (2004) e Gomes Júnior, Sá e Valério Filho (2008) não obtiveram efeitos significativos no número de grãos por vagem com a utilização de diferentes doses de $\mathrm{N}$ aplicada em cobertura.

A massa de 100 grãos também não teve influência dos manejos de $\mathrm{N}$ aplicadas em nenhuma das safras de cultivo (Tabela 1). Esses resultados encontram respaldo aos observados por Gomes Júnior, Sá e Valério Filho (2008), que não constataram diferença significativa para a massa de 100 grãos do feijoeiro quando submetido a doses e épocas de aplicação de $\mathrm{N}$ em sistema de plantio direto. Soratto, Carvalho e Arf (2004) também observaram que o $\mathrm{N}$ em cobertura não proporcionou efeito significativo na massa de 100 grãos. Para Soratto, Carvalho e Arf (2004), doses de N não causam grande variação na massa de 100 grãos, e essa é uma das características que apresenta pequena variação, em função das alterações no meio de cultivo.

A produtividade de grãos do feijoeiro foi influenciada significativamente pelos manejos de N durante a safra "das águas" (Tabela 1). A produtividade de grãos do tratamento referência (M1) diferiu apenas da testemunha (M5), com valor $24 \%$ superior a esta. Os manejos baseados no clorofilômetro (M3 e M4) não diferiram do tratamento referência (M1), porém, proporcionaram a utilização de menores quantidades de $\mathrm{N}$ na adubação, e, apesar de também não terem diferido estatisticamente da testemunha, os manejos M3 e M4 proporcionaram produtividades de $8 \%$ e $13 \%$ superiores ao tratamento sem aplicação de $\mathrm{N}$ (testemunha), respectivamente. O manejo M4 (baseado no ISN de 90\%) apresentou maior eficiência de utilização do $\mathrm{N}$ aplicado (EU), quando comparado com o manejo M3 (baseado no ISN de 95\%) (Tabela 1). No tratamento M4 a aplicação de $\mathrm{N}$ em cobertura consumiu $150 \mathrm{~kg} \mathrm{ha}^{-1}$ a menos, em comparação, com o manejo M1 (referência), e o manejo M3 que recebeu $90 \mathrm{~kg} \mathrm{ha}^{-1}$ a menos que o
M1. Apesar do manejo M4 ter proporcionado maior EU, a produtividade de grãos neste tratamento foi $307 \mathrm{~kg} \mathrm{ha}^{-1}$ inferior ao tratamento referência (M1).

A produtividade de grãos obtida na safra "da seca" não foi influenciada pelos manejos de $\mathrm{N}$ (Tabela 1). O manejo M1 promoveu produtividade de grãos 13\% superior à testemunha (M5). Os manejos de $\mathrm{N}$ baseados no monitoramento com o clorofilômetro levaram a incrementos de $16 \%$ (M3) e 10\% (M4) superiores a testemunha (M5). $\mathrm{O}$ fato de o tratamento testemunha apresentar produtividade de grãos elevada pode ser atribuído ao fornecimento do $\mathrm{N}$ pela fixação simbiótica do $\mathrm{N}_{2}$ e/ou pela mineralização dos resíduos das culturas anteriores. O manejo M4 também proporcionou maior valor de EU (Tabela 1). Esse manejo recebeu a aplicação de apenas $20 \mathrm{~kg} \mathrm{ha}^{-1}$ de $\mathrm{N}$ na semeadura, por não ter apresentado deficiências de $\mathrm{N}$ o longo do ciclo, consumindo assim, $180 \mathrm{~kg} \mathrm{ha}^{-1}$ de $\mathrm{N}$ menos, que manejo M1 (referência).

Em ambas as safras, o manejo M4 proporcionou utilização de menor quantidade de $\mathrm{N}$, sem redução da produtividade de grãos, em comparação com o tratamento M2 baseado na recomendação local (AMBROSANO et al., 1997), ou seja, promoveu economia de $\mathrm{N}$ em relação à dose rotineiramente utilizada (Tabela 1). Assim, os resultados são indicativos de que o monitoramento com o clorofilômetro portátil, utilizando como critério de decisão o ISN $<90 \%$ em relação à área referência, pode evitar aplicação desnecessária de $\mathrm{N}$ em cobertura no feijoeiro, proporcionando redução dos custos de produção e os riscos ambientais.

A utilização do ISN de $90 \%$, calculado com base no monitoramento do IRC nas folhas com o clorofilômetro portátil, é mais eficiente que o de 95\% para a definição de quando se deve aplicar o $\mathrm{N}$ em cobertura no feijoeiro cultivar IAC Alvorada, possibilitando o uso de menores doses de N, com maior eficiência do fertilizante aplicado. 


\section{Referências}

AMBROSANO, E. J.; TANAKA, R. T.; MASCARENHAS, H. A. A.; RAIJ, B. van; QUAGGIO, J. A.; CANTARELA, H. Leguminosas e oleaginosas. In: RAIJ, B. van; CANTARELA, H.; QUAGGIO, J. A.; FURLANI, A. M. C. (Ed.). Recomendações de adubação e calagem para o Estado de São Paulo. 2. ed. Campinas: Instituto Agronômico e Fundação IAC, 1997. p. 187-203. (Boletim técnico, 100).

BARBOSA FILHO, M. P.; COBUCCI, T.; FAGERIA, N. K.; MENDES, P. N. Determinação da necessidade de adubação nitrogenada de cobertura no feijoeiro irrigado com auxílio do clorofilômetro portátil. Ciência Rural, Santa Maria, v. 38, n. 7, p. 1843-1848, 2008.

Época de aplicação de nitrogênio no feijoeiro irrigado monitorada com auxílio de sensor portátil. Ciência e Agrotecnologia, Lavras, v. 33, n. 2, p. 425-431, 2009.

BREDEMEIER, C.; MUNDSTOCK, C. M. Regulação da absorção e assimilação do nitrogênio nas plantas. Ciência Rural, Santa Maria, v. 30, n. 2, p. 365-372, 2000.

CHAPMAN, S. C.; BARRETO, H. J. Using a chlorophyll meter to estimate specific leaf nitrogen of tropical maize during vegetative growth. Agronomy Journal, Madison, v. 89, n. 4, p. 557-562, 1997.

GOMES JÚNIOR, F. G.; SÁ, M. E.; VALÉRIO FILHO, W. V. Nitrogênio no feijoeiro em sistema de plantio direto sobre gramíneas. Acta Scientiarum Agronomy, Maringá, v. 30, n. 3, p. 387-395, 2008.

JEMISON, J. M.; LYTLE, D. E. Field evaluation of two nitrogen testing methods in maize. Journal Production Agriculture, Madison, v. 9, n. 1, p. 106-113, 1996.

MALAVOLTA, E.; VITTI, G. C.; OLIVEIRA, S. A. Avaliação do estado nutricional de plantas: princípios e aplicações. Piracicaba: Potafos, 1997. 308 p.
SANT'ANA, E. V. P.; SANTOS, A. B.; SILVEIRA, P. M. Adubação nitrogenada na produtividade, leitura SPAD e teor de nitrogênio em folhas de feijoeiro. Pesquisa Agropecuária Tropical, Goiânia, v. 40, n. 4, p. 491-496, 2010.

SILVEIRA, P. M.; BRAZ, A. J. B. P.; DIDONET, A. D. Uso do clorofilômetro como indicador da necessidade de adubação nitrogenada em cobertura no feijoeiro. Pesquisa Agropecuária Brasileira, Brasília, v. 38, n. 9, p. 1083-1087, 2003.

SILVEIRA, P. M.; DAMASCENO, M. A. Doses e parcelamento de $\mathrm{K}$ e de $\mathrm{N}$ na cultura do feijoeiro irrigado. Pesquisa Agropecuária Brasileira, Brasília, v. 28, n. 11, p. 1269-1276, 1993.

SOARES, A. L. L.; FERREIRA, P. A. A.; PEREIRA, J. P.; VALE, H. M. M.; LIMA, A. S.; ANDRADE, M. J. B.; MOREIRA, F. M. S. Eficiência agronômica de rizóbios selecionados e diversidade de populações nativas nodulíferas em Perdões (MG): II - feijoeiro. Revista Brasileira de Ciência Solo, Viçosa, v. 30, n. 5, p. 750$758,2006$.

SORATTO, R. P.; CARVALHO, M. A. C.; ARF, O. Nitrogênio em cobertura no feijoeiro cultivado em plantio direto. Revista Brasileira de Ciência do Solo, Viçosa, v. 30, n. 2, p. 259-266, 2006.

Teor de clorofila e produtividade do feijoeiro em razão da adubação nitrogenada. Pesquisa Agropecuária Brasileira, Brasília, v. 39, n. 9, p. 895-901, 2004.

VARVEL, G. E.; SCHEPERS, J. S.; FRANCIS, D. D. Ability for in-season correction of nitrogen deficiency in corn using chlorophyll meters. Soil Science Society of America Journal, Madison, v. 61, n. 4, p. 1233-1239, 1997. 